University of Missouri, St. Louis

IRL@ UMSL

Theses

UMSL Graduate Works

3-19-2010

\title{
The Nature of Fictional Characters
}

Katherine Celeste Tullmann

University of Missouri-St. Louis

Follow this and additional works at: https://irl.umsl.edu/thesis

Recommended Citation

Tullmann, Katherine Celeste, "The Nature of Fictional Characters" (2010). Theses. 254.

https://irl.umsl.edu/thesis/254

This Thesis is brought to you for free and open access by the UMSL Graduate Works at IRL @ UMSL. It has been accepted for inclusion in Theses by an authorized administrator of IRL @ UMSL. For more information, please contact marvinh@umsl.edu. 


\title{
THE NATURE OF FICTIONAL CHARACTERS
}

by

Katherine C. Tullmann

B.A., Philosophy \& Religion, English, Truman State University, 2008

\author{
A THESIS \\ Submitted to the Graduate School of the \\ UNIVERSITY OF MISSOURI-ST. LOUIS \\ In Partial Fulfillment of the Requirements for the Degree \\ MASTER OF ARTS \\ in \\ PHILOSOPHY \\ March, 2010 \\ $\underline{\text { Advisory Committee }}$ \\ Stephanie Ross, Ph.D., \\ Committee Chair \\ Berit Brogaard, Ph.D. \\ Eric Wiland, Ph.D.
}

CCopyright 2010

By

Katherine C. Tullmann

All Rights Reserved 
Tullmann, Katherine C. 2010, UMSL, p. 2

\begin{abstract}
This paper explores the ramifications of a central question concerning our everyday experience with film and other art forms: how it is possible to recognize a character in a sequel or related artwork as the exact same character as that found in the original or previous artwork. My main goal is to determine necessary and sufficient identity conditions for fictional film characters which may adequately account for our everyday discussion of these characters. After addressing several intuitions which any theory of fictional characters must address, I propose that film and other characters should be best understood as "abstract artifacts" following the Amie Thomasson's artifactual theory of fictional characters. I then propose Thomasson's theory as the best way to explain fictional characters and apply her theory to film characters, before addressing two interesting and problematic examples of film characters.
\end{abstract}




\section{The persistence of characters}

Our favorite characters of film and literature often reappear in multiple works: Indiana Jones stars as the hero in his own adventure trilogy and Sherlock Holmes as the cunning detective in Arthur Conan Doyle's many stories. Also, film characters often originate as literary ones: Emma Woodhouse was a fictional character in Jane Austen's novel Emma before she made it to the big screen, and James Bond, though taking on many guises in the several decades of his film history, originated as a character in a series of novels upon which the movies are based. In both cases, viewers typically recognize the fictional character as the same figure that appeared in a previously made film, even if she first started as a literary figure or if different actors portray the same character in different movies.

Recognizing a fictional character across media (usually from literature to film) and also within the same medium (as in sequels or parodies) raises interesting questions regarding the nature of fictional character identity-how is it that the same character can appear in different art works? Furthermore, this question presupposes other ontological issues concerning fictional characters and the status of film as a unique art form. The ontological status of fictional characters has been questioned by various philosophers, many of whom conclude that they are non-real, mind-dependent entities created by an author, possessing no spatiotemporal existence. To argue otherwise would be to allow troublesome non-real entities into one's ontological perspective, a view which many philosophers are unwilling to take.

In her text Fiction and Metaphysics, Amie Thomasson addresses a problem facing 
philosophers who wish to explain the ontological status of fictional characters: many philosophers dealing with fictional characters start with a pre-conceived ontology, and attempt to fit fictional entities into it. Thomasson, on the other hand, argues that one must first explore what it means for fictional entities to exist and then elaborate on what requirements an ontological theory must have in order to account for them.

Like Thomasson, I wish to interpret fictional film characters in terms of our everyday experience of them-how we normally think of the creation, existence and persistence of fictional characters. From there we can determine what sort of ontological picture is required to account for fictional objects. This is an important question for philosophy as a whole; surely no general ontology would wish to deny some explanation of the nature of fictional objects. Thus, I suggest that any ontological account of fictional objects must address several intuitions we typically have about them. Several of these include:

1. Fictional characters (including film characters) have a different kind of existence from other ordinary objects of our experience. ${ }^{1}$

2. Film characters appear in more than one story of the same or different medium and can nevertheless still be the same character.

3. Film characters are created.

4. Film characters are different from characters in other art forms.

5. Everyday audience viewers can meaningfully discuss fictional characters.

The first intuition seems unquestionable-despite the fact that films can be incredibly life-like competent viewers of films know that they cannot go out into the world and find Leonard Shelby from Christopher Nolan's Memento roaming the streets of L.A. That is, if film characters do exist, they exist in a different way than other people or objects we encounter in our daily

\footnotetext{
${ }^{1}$ As a ground work for this paper, I define fictional characters similarly to Thomasson, as "characters [that] appear in works of fiction and whose fortunes we follow in reading those works" (5) We mostly think of humans portrayed in artworks when we think of characters, but we can extend the definition to other things, such as animals or inanimate objects, as well.
} 
lives. The basis for the second intuition seems undeniable. As mentioned in the opening paragraph, no one questions that the Harry Potter of The Sorcerer's Stone is the same as Harry Potter in The Chamber of Secrets. This is implicitly understood in both filmmaking and viewingotherwise we would have to explain how two remarkably similar young boys appear in such similar stories with the same history and life circumstances. The third intuition assumes that fictional characters do not have any sort of existence before an author creates them-they are not a member of a Platonic realm of abstracta or a citizen of a possible world, but rather created, through a linguistic act, by a person at a certain point in time. The fourth intuition seems correct but difficult to explain. Film characters are very similar to literary characters and especially dramatic characters. But what makes film a unique art form also makes film's characters different from characters in other media. They depend, necessarily, on real people and the real world in order to exist-namely, the actors who portray them and the set around them. ${ }^{2}$ The question becomes, then, what are the philosophical or ontological ramifications for understanding film as a unique art form? This is a question that will be addressed throughout the course of this paper. The final intuition implies that, when we discuss fictional characters, we are speaking of actual objects; I will argue that a realist theory of fictional characters can best account for this.

Throughout this paper, I will utilize Thomasson's realist artifactual theory of fictional characters as the basis for understanding film character's identity conditions. Thomasson offers an account of fictional characters as contingent, abstract artifacts; entities which exist in the same manner as other cultural artifacts, such as state laws or the U.S. Constitution. However,

\footnotetext{
${ }^{2}$ This, of course, does not include animated or completely CG characters. These characters present their own categorical problems, which I will briefly address in the conclusion of this paper. This condition also seems to apply to dramatic characters - In section 6 I will attempt to differentiate between these two media.
} 
while Thomasson focuses mainly on literary fictional characters, I would like to explore her view as applied to film's fictional characters. Thomasson recognizes the ontological distinctions between painting, sculpture and other art forms on the one hand, and narrative artworks such as drama and literature on the other. Though perhaps more similar to the latter group, film nevertheless presents unique philosophical questions in the debate about the status of fictional characters. In this paper I will argue for the persistence of film characters based on Thomasson's artifactual definition, with special focus on the aspects of film which make it a unique art form with a different ontological status than the others which Thomasson discusses.

\section{Thomasson's artifactual theory ${ }^{i}$}

Thomasson's artifactual theory describes fictional characters as abstract artifacts-objects which have no spatiotemporal location (and, so, are $a b s t r a c t^{3}$ ), but can nevertheless really be said to exist-not as objects of make-believe, a la Walton, ideal abstracta according to Meinongians, or as real but unactual citizens of another possible world.

Fictional characters are not alone in being "abstract" artifacts-Thomasson lists everyday objects such as theories, laws, governments and literary works as similar entities. Like fictional characters, these objects are "tethered to the everyday world around us" by their relation to their creators and copies of their instantiation onto a physical object (e.g. a written down or spoken law). ${ }^{4}$ Fictional characters can be found "in" literary works, but here a similar question arises-where are literary works, if anywhere? We possess copies of Emma, but the work itself does not exist in a particular location; neither does the character Emma exist in the

\footnotetext{
${ }^{3}$ Thomasson 37.

${ }^{4}$ Ibid xi.
} 
location of a copy of the novel. ${ }^{5}$ Furthermore, we must treat fictional characters as abstract artifacts because they cannot be located in the locations or time they are purportedly supposed to be-if we were to drive the thirty some-odd minutes south from London to find the manor Hartfield in Surrey and hope to find Emma Woodhouse waiting inside, we would be disappointed-both in not finding Emma there and in making a strange categorical mistake. Competent readers understand this as they engage with fictions. However, as Thomasson states, "[i]n our everyday discussion of literature we treat fictional characters as created entities brought into existence at a certain time through the acts of an author." ${ }^{6}$ The sense in which fictional characters do seem to be real to us stems from their created nature: (quote) "We do not describe authors as discovering their characters or selecting them from an ever-present set of abstract, nonexistent or possible objects. Instead, we describe authors as inventing their characters, making them up, or creating them, so that before being written about by an author, there is no fictional object....a work of fiction is necessarily tied to its particular origin" ${ }^{\prime 7}$ The fact that fictional characters are created entities proves to be of vast importance in explaining their dependence relations and identity conditions.

Thomasson must also explain how fictional characters as abstract artifacts continue to exist, even if their author ceases to be. It seems obvious that, once a character has been created, it can continue to exist even without its author. Fictional characters do necessitate, though, that the copies of the literary work in which they appear remain in existence in order for them to do the same. ${ }^{8}$ Characters and the literary works in which they are included do not depend on a specific copy in order to remain in existence-any copy will do. Furthermore,

\footnotetext{
${ }^{5}$ Ibid 37.

${ }^{6}$ Ibid 5.

${ }^{7}$ Ibid 6, 7.

${ }^{8}$ Ibid 7.
} 
literary works can be preserved in physical copies and also in one's memory, as in the oral folktales of Appalachia Thomasson cites which are not written down. Once all copies and memories of a literary work cease to exist, we cannot reasonably say that the fictional characters in that story remain. ${ }^{9}$ That does not necessarily mean that the fictional character can no long be referred to or thought of. Thomasson likens the "death" of a fictional character to that of a human: "we may still think of and refer to people after they have died, buildings long since destroyed, civilizations long gone by. If fictional characters and literary works cease to exist, I am not suggesting that they then enter a peculiar realm of Meinongian nonexistence or that it is as if such objects never were, but rather that they become past objects just like the other contingent objects around us."10

It may also seem unclear as to how an author brings a fictional character into existence. Thomasson explains that this occurs through a linguistic act. Fictional characters seem unlike other artifacts in that their creation to come from merely describing an object; they are: "created merely with words that posit them as being a certain way."11 For example: "Jane Austen creates the fictional character Emma Woodhouse and brings her into existence (assuming she did not exist before) in writing the sentence: 'Emma Woodhouse, handsome, clever, and rich, with a comfortable home and happy disposition, seemed to unit some of the best blessings of existence, and had lived nearly twenty-one years in the world with very little to distress or vex her.'”12 Creation through speech acts might seem implausible, but we recognize other linguistic acts having a similar creative power. "Conventional" or "effective illocutionary acts" such as appointing, resigning, adjourning and marrying also bring into existence the state

\footnotetext{
${ }^{9}$ Ibid 10.

${ }^{10}$ Ibid 11.

${ }^{11}$ Ibid 12.

${ }^{12}$ Ibid 12.
} 
of affairs which they describe. ${ }^{13}$ When a CEO adjourns a business meeting, his linguistic act of calling the meeting to a close actually performs the action which it describes. Similarly, an author describes a character which, in effect, performs the linguistic act of bringing a fictional character into existence by ascribing her with certain properties.

\section{Dependence relations}

As we can see, fictional characters depend on two distinct physical objects in order to exist: their author/creator and copies (mental or physical) that instantiate the character in a literary work. Our main concern when dealing with fictional characters has to do with their existential dependence: Necessarily, if $\alpha$ exists, then $\beta$ exists; so $\alpha$ depends on $\beta$ for its existence. ${ }^{14}$ There are two types of dependence which are related more specifically to fictional characters' relation to physical objects: constant dependence and historical dependence. In the general picture of existential dependence, the times of existence for both $\alpha$ and $\beta$ are unspecified. Constant dependence is "a relation such that one entity requires that the other entity exist at every time at which it exists. ${ }^{15}$ This means that, necessarily, whenever $\alpha$ exists, $\beta$ must also exist. If the "founding entity" $(\beta)$ is an individual or particular, then the dependence is rigid. For example, I am constantly rigidly dependent on my brain in order to exist; the redness of an apple is constantly rigidly dependent on the existence of that apple. ${ }^{16}$ Generic dependence requires that the founding entity is not a particular individual, but rather an unspecified object or state of affairs. For example, Thomasson argues that at any given time that the United States exists, there must be some person that possesses the property of being a citizen of that country,

\footnotetext{
${ }^{13}$ Ibid 12.

${ }^{14}$ Ibid 25.

${ }^{15}$ Ibid 29.

${ }^{16}$ Ibid 30.
} 
though no person in particular is required. ${ }^{17}$ Historical dependence, which involves the relation required for an object's coming into existence, is a weaker dependence relation than constant dependence. This is "a relation such that one entity requires that the other entity exist at some time prior to or coincident with every time at which it exists." ${ }^{18}$

Fictional characters are dependent on their author and on their literary work. The author/character relation can be described as a rigid historical dependence. A fictional character is created by a particular author, but once created the author need not always exist for the character to. Fictional characters are also generically constantly dependent on their literary works - they do not rely on a particular copy of a literary work in order to exist, merely some literary work, and one copy of the literary work must always be in existence in order for the fictional character to remain so. ${ }^{19}$

\section{An issue of identity}

Thomasson provides an interesting thought experiment which highlights the difficulty of recognizing characters across literary works in the context of discounting other, property-based theories of characters-particularly Meinongian and possibilist theories. ${ }^{20}$ According to property-based theories, if a character in one art work has the exact same properties as the character in another, then they are the same character. This seems to make sense; this is how we recognize a character from work to work. But we run into problems when considering the identity conditions property-based characters imply.

\footnotetext{
${ }^{17}$ Thomasson 31.

18 Ibid 29.

19 Ibid 35, 36.

${ }^{20}$ See note i.
} 
One of the consequences of a theory of fictional objects which relies on properties is that it is possible for two authors to, intentionally or accidentally, create the exact same character. Along the same line, if two characters have different properties, they are not the same character.

Thomasson uses an example of Samuel Richardson's and Henry Fielding's different portrayals of the virtuous maid Pamela to show how two instances which have different properties nevertheless should be understood as the same character:

Our critical practices presuppose that Richardson's Pamela of Pamela and Fielding's Pamela of Joseph Andrews concern the same character, invented by Richardson, and referred to by Fielding, who attributes new properties to her in his parody. By contrast...if a student should turn up an unknown tale about maid called 'Pamela' and the attempts of a squire to seduce her, and if that tale were in no way connected to Fielding's or Richardson's work, making it pure coincidence that there were such characters, we would with justice regard these Pamela's as merely remarkably similarbut distinct-characters.... ${ }^{21}$

Because according to the property-based views two objects are identical if, and only if, they have exactly the same properties, these theories must accept the student's Pamela and Richardson's Pamela as the same character, even if they are created merely accidentally, while Fielding's Pamela is a different character from Richardson's, even though he intentionally wrote his Pamela to be the same. ${ }^{22}$ Similar problems occur with characters in sequels-if even one property is changed, then it is no longer the same character. ${ }^{23}$ As we will see in Thomasson's theory, fictional characters depend on more than their properties to be understood as the same character across works-literary conditions as well as the author's intention both play a role as well.

Identity conditions

\footnotetext{
${ }^{21}$ Thomasson 56.

${ }^{22}$ Ibid 57.

${ }^{23}$ Ibid 57.
} 
One of the problems encountered by other theories of fictional characters, including the Meinongian and possibilist theories, has to do with identifying characters based on properties. This was the difficulty in distinguishing Richardson's Pamela from the student's, while not being able to explain how Fielding and Richardson's were the same character. The artifactual theory, Thomasson argues, can provide meaningful identity conditions for fictional characters without relying on the character's properties to make sense of them. As she says, "Similar characters do not the same characters make (nor do dissimilar characters different characters make)." ${ }^{24}$ Instead, Thomasson explains character's identity conditions in terms of their dependence relations.

There are two central problems in addressing the identity conditions for fictional characters: explaining how a character can be the same within a literary work and also how a character can be the same across two or more literary works. Thomasson provides sufficient conditions for the former, and a necessary condition for the latter. Together, she argues, these identity conditions can provide an adequate explanation of how characters persist.

There are two conditions sufficient for fictional characters $\mathrm{x}$ and $\mathrm{y}$ to be identical:

1. $x$ and $y$ appear in the same literary work.

2. $x$ and $y$ are ascribed exactly the same properties in the literary work. ${ }^{25}$

By "appearing in a literary work," Thomasson means simply that the character is ascribed some property in that work. The second condition ensures that a fictional character is unique within a work; $x$ and $y$ must have the same properties so that they can be distinguished from other characters in the same work.

The first condition is important in that it helps to explain how different readers of the

${ }^{24}$ Ibid 62.
${ }^{25}$ Ibid 63. 
same literary work can be understood as reading about the same character. This condition also assumes that literary works have their own identity conditions, as well as the characters within them. In order to explain this point, Thomasson distinguishes between a text type, composition and literary work. Two stories which have exactly the same string of linguistic characters, and in the same order, are of the same text type. ${ }^{26}$ For example, in Jorge Luis Borges' story “Pierre Menard, Author of the Quixote," Menard's Quixote is of the same text type as Cervantes' because the words are exactly the same in both stories. However, Cervantes' and Menard's Quixote are not the same composition. This is because a composition is a text type created by "a certain author in certain historical circumstances." ${ }^{27}$ As in Borges' example, it could be completely coincidental that two authors write compositions which happen to have the same text type. Furthermore, having the same text-type and same composition does not ensure that $x$ and $y$ are the same literary work. A literary work differs from a composition in that it takes into account "certain aesthetic and artistic qualities" of a story as well as how the story is tells a certain tale "concerning various characters and events." ${ }^{28}$ Literary works require that there is a certain community of people who speak the right language and have the correct background assumptions in order to be able to read and understand the story. It is possible that a story with the same text type and composition are different literary works, if they are read by two cultures that are significantly different to the extent that they interpret the aesthetic qualities and meaning of the story differently. ${ }^{29}$

Thus, two stories are instances of the same literary work if they are the same composition and also require the same background assumptions and language of their readers.

\footnotetext{
${ }^{26}$ Ibid 64.

${ }^{27}$ Ibid 64.

${ }^{28}$ Ibid 64.

${ }^{29}$ Ibid 65.
} 
This definition of literary work ensures, Thomasson argues, that two readers of Emma are reading about the same character. It also explains how Richardson and the student's Pamelas are distinct characters ${ }^{30}$-as with Menard and Cervantes' Quixotes, we can say that Richardson and Jones have stories of the same text type, but not the same literary work.

In order to explain how Richardson and Fielding's Pamelas are the same character, we must also provide identity conditions for fictional characters across literary works. Thomasson provides a necessary condition for this: for characters $x$ and $y$ appearing in literary works $K$ and $L$, respectively, "The author of $L$ must be competently acquainted with $x$ of $K$ and intend to import $x$ into $L$ as $y . " 31$ "Competent acquaintance" of a character ensures that the author understands how the name $x$ is used in $K$. The author of $L$ can then refer to $x$ in $L$ (as $y$ ), and even ascribe new properties to $x$ in this new literary context. We can assume, for example, that Tom Stoppard was competently acquainted with Rosencrantz and Guildenstern in Hamlet and included them into his own drama as the same characters.

\section{An objection \& reply}

Sainsbury provides several objections to Thomasson's (and others) artifactual theory, including many which involve complex arguments stemming from the philosophy of language. However, Sainsbury's most pressing concern seems to be also his most basic: in our everyday speaking and thinking about fictional characters, we do not think of them as abstract. He states:

When we think about fictional entities, we do not think of them as abstract. Authors, who ought to know, would fiercely resist the suggestion that they are abstract. Abstract artifact theory entails that producers and consumers of fiction are sunk in error.

Fictional characters do not have any of the properties they are ascribed during their creation. This is mysterious: Conan Doyle stipulates that Holmes wears a deerstalker,

\footnotetext{
${ }^{30}$ Ibid 66.

${ }^{31}$ Ibid 67.
} 
there is such an entity as Holmes, yet that entity does not end up having (i.e. exemplifying) the property of wearing a deerstalker. He does end up having (exemplifying) a genuine property, that of encoding wearing a deerstalker, but this is not a property that's intellectually accessible to most authors. People can, of course, fail to understand what they are doing, but it's surprising to be told that so many authors, perhaps all, fail so often and so seriously. ${ }^{32}$

The first task in responding to Sainsbury's argument is in understanding what he means by fictional characters possessing a certain property. Properties can be related to abstract artifacts in two ways: exemplifying and encoding. Encoded properties are "those ascribed in the story," while exemplified properties are "those the entity really possess." ${ }^{33}$ All abstract artifacts, Sainsbury argues "exemplify the property of being abstract and of having been created by human agency." On the other hand, Sherlock Holmes, for example, "encodes the property of being a detective and playing the violin." ${ }^{34}$ These are properties with Holmes as an artifact cannot exemplify, because Holmes lacks spatiotemporal location. Thus, Holmes "encodes but does not exemplify the property of being a detective. He exemplifies but does not encode the property of having been created by human agency." ${ }^{35}$

I will respond to Sainsbury's argument point by point. He first argues that authors typically do not think of their fictional characters as abstract. This is what allows authors, by the artifactual theory, to ascribe certain properties to them. However, I do not think that most authors genuinely believe that their characters exist in a non-abstract way (i.e., possessing spatiotemporal location). They may write about their characters as if they existed somewhere (in the world of the work, perhaps), and this may be ontologically problematic in its own way, but an author does not believe that the character she is creating with her intentional and

\footnotetext{
${ }^{32}$ Sainsbury 111.

${ }^{33}$ Ibid 93.

${ }^{34}$ Ibid 93.

${ }^{35}$ Ibid 93.
} 
linguistic acts is thereby taking on a flesh and blood existence. It would be absurd to think so.

Furthermore, this would entail a category mistake similar to what Crittenden argues takes place within Russell and Quine's description theory. We may speak as if fictional characters are not abstract, but any competent reader would know that the objects of fictional do not exist in the world around us. It is a limitation of our language that it only recognizes an ontological bifurcation between real or existing and not real and not existing. We do not have the capability to discuss abstracta in any other way. Consider the similar example of mathematical objects. Mathematicians (who ought to know better) and students speak about geometrical shapes and other mathematical objects in a way which might suggest that the object under discussion is real somewhere in the physical world-in the classroom, perhaps. But the mathematician, like authors and readers of literary works, at the same time knows that the objects under discussion, which they speak of as possessing certain properties, are anything but abstract.

That does not stop us from ascribing properties to fictional characters. Sainsbury states, though, that this is a false ascription - that abstract objects cannot have the properties which their authors wish them to have. He states that "[f]ictional characters do not have any of the properties they are ascribed during their creation." But why don't they? Meinongian theories (which Sainsbury favors over Thomasson's artifactual theory) argue that abstract objects can possess properties. Thomasson's view assumes the same. By Sainsbury's own definitions, fictional characters encode but do not exemplify the properties which authors ascribe to themthey have those properties within the story, but do not really possess them. This seems to be a misunderstanding on Sainsbury's part about an author's creative process which Thomasson describes. Consider the Emma Woodhouse example noted above. In ascribing the character 
Emma certain properties in the story, Jane Austen at the same time creates the fictional character. It is her linguistic act which both creates the abstract artifact, Emma, and ascribes properties to the characters. Thus, the encoded properties are also exemplified, according to the artifactual theory.

Sainsbury concludes, then, that authors must be wrong in their assumption that their characters really exist, and this is an unwanted conclusion. Surely authors of fiction should be the experts in their field. I do not see Sainsbury's point, that authors do not understand the method of their ascribing properties to characters (exemplifying and encoding) as problematic to an artifactual theory. Many authors who have a strong background in literary theory nevertheless understand little about philosophy of literature or language. This does not mean that they are poor authors-or not authors at all. Most people would not assume that an author of fictions needs to possess a background in philosophy in order to be genuinely creative.

IV. Are film characters abstract artifacts?

Because of her realist understanding of fictional characters, Thomasson is able to account for problematic cases of identity conditions which plague other theories. Throughout her discussion, however, she focuses on literary figures. It is my task to explain how her theory might also be understood in terms of film characters.

Identity conditions (the narrative arts)

When speaking of fictional characters, the art forms that most typically come to mind include literature, drama and film. These art forms also lend themselves most readily to an artifactual theory because their fictional characters may appear in sequels or other related 
works. The difficulty comes in distinguishing between these three art forms, establishing what it is that makes each its own, unique art form. One of the distinguishing features of film, I argue, has to do with its identity conditions and dependence relations.

Literarture, drama and film possess different identity conditions than even paintings and statues. One thing that these art forms all have in common has to do with what Noël Carroll calls a type-token relationship. ${ }^{36}$ For example, my copy of Emma is a token (an individual instance) of the type (the artwork itself) written by Jane Austen; my edition is not the artwork itself. This relates back to Thomasson's point that a literary work is not historically dependent on a specific copy (token) of the work. Furthermore, this applies to film and drama as well as literary works: a viewing of the film The Royal Tenenbaums is a token of the type written and directed by Wes Anderson, but cannot be equated with the artwork itself because there are so many copies of this film available. We do not recognize the performance of a play to be the artwork itself, but rather a token of the work, actors, directors and stagehands can make mistakes or slight accommodations for a specific venue to a piece and still have it remain a token of the same artwork. This is different than with paintings or sculpture, in which a modification of a physical property of the work results in a change to the work itself. The kinds of changes that films and plays can undergo are different: the actual performance of a play can vary slightly night to night, or the projection of a movie can be flawed so that what the audience sees in a theater one night is different from what they would see in subsequent viewings. However, one cannot take out significant sections of Pride and Prejudice and replace them with other sentences, the way one can restore the paint on the Last Supper or the bronze of a Lincoln statue.

Where do fictional characters fit in this understanding of an artwork's identity

\footnotetext{
${ }^{36}$ Carroll 65.
} 
conditions? According to an irrealist view, the properties a character is meant to possess are an important aspect of their identity and what makes them recognizable across artworks. Figures whose properties change significantly from one fictional work to the next may not seem to be the same character. James Bond of Goldfinger is quite unlike the James Bond of Casino Royale, the former possessing a wry humor and nonchalant air lacking in the latter, not to mention a darker complexion and hair color. Likewise, Jane Austen's Emma is described as a 20 year-old brunette, while Gwyneth Paltrow's portrayal of Emma Woodhouse is an older, blonder and thinner version of the original. Should we say, then, that these are different characters-that Emma of the novel is a different Emma than that of the film?

This view appears problematic for how we typically discuss and understand fictional characters. We automatically understand that a character in a sequel is the same as the character in the original, and thus attribute to the former the same defining characteristics, life history and situation as the latter. For example, we understand that Luke Skywalker from The Return of the Jedi is the same character as he was in The Empire Strikes Back-albeit a more somber and far wiser version of himself. We do not attribute the changes in Luke's character to the fact that we are actually witnessing two different Luke's, but rather to the life experiences and emotions which we assume he has undergone from the time of the second movie to that of the third. We would argue that the character of Luke persists despite changes in properties from one film to the next.

Thomasson believes that her artifactual theory can explain away problems concerning the identity conditions of fictional characters. The artifactual theory argues that fictional characters are created by authors (as opposed to part of a possible world or realm of abstract entities) and so are subject to changes that the author may chose to make. The same character 
may appear in a sequel, prequel or parody because Thomasson bases character identity on historical continuity rather than sameness of properties. A character like Faulkner's Dr. Peabody may appear in different stories even if an author changes some of the character's properties among works. The same can be said for film characters: Jay and Silent Bob are the same characters with many of the same properties in all of Kevin Smith's movies from Dogma to Jay and Silent Bob Strike Back, even if some of the properties of the characters have changed between roles. This would also be the case for changes in properties between media-a character in a novel can possess different properties from those in a movie, but still be understood as the same character.

Consider again Thomasson's necessary and sufficient conditions for character identity. It is possible to understand Luke Skywalker in The Empire Strikes Back as the same character throughout the film because, for any two appearances of that character, he satisfies the two sufficient conditions of appearing in the same work and with the same properties. Luke Skywalker also provides a straightforward example of Thomasson's necessary condition for characters across works as well-George Lucas was appropriately acquainted with the character Luke from The Empire Strikes Back and, because of this, was able to create the same character in the film's final chapter, The Return of the Jedi.

\section{Dependence relations}

Luke remains an easily recognizable character throughout the Star Wars original trilogy, despite slight modifications in his properties. Other cases, such as the James Bond films, are not so easily explained. Part of this has to do with the unique dependence relations which films possess. While literary characters have a dual dependence on an author for creation and copies 
or tokens for their persistence, the fictional characters of film have, I argue, two additional dependence relations: counterfactually on the physical world and creatively on the actors who portray them. These dependence relations not only explain in what way film characters are artifacts of the physical world, but also help to distinguish film ontologically from literature and drama.

Film characters are both created and rely on copies or tokens of their artwork in order to remain in existence. So far, this is compatible with the fictional characters of literature. The first dependence relation, concerning character as created artifacts, is a more complex issue when discussing film than with literature. We typically think of the act of creating a literary character as a solitary one-we only attribute one author to most stories. The issue of authorship for film characters is less straightforward, as it is unclear who earns the title of 'author' for any given film. ${ }^{37}$ Many people take it for granted that the director is the true author of a film, especially if the director also wrote the screenplay and played a very integral role in editing the film and directing its cinematography. This is the case for several contemporary filmmakers, including Quentin Tarantino and Wes Anderson. When it comes to the creation of individual characters, though, we might also wish to grant the actor portraying the character some form of creativity. The issue of film authorship is a complicated one, and it is beyond the scope of this paper to answer it definitively. Suffice it to say that film characters do seem to be created-as opposed to unactualized figures from another possible world, or a person-type from a Meinongian realm.

Film characters also depend on a person (or persons) in the physical world in order to come into existence-that is, they are historically dependent on an author. Film characters, like literary ones, are also constantly dependent on copies/tokens of their artwork in order to

\footnotetext{
${ }^{37}$ For a more thorough discussion of film authorship, see Carroll 2008 or Thomson-Jones 2009.
} 
remain in existence. If no copy (DVD, VHS, film reel, memory of the artwork, etc.) remains of a film in which a certain character appears, then the character ceases to exist along with the artwork.

One of the unique features of film as an art form is its counterfactual dependence on the actual world. When employing traditional methods of filming, what the viewer sees in a film counterfactually depends on what exists in reality. Kendall Walton uses the example of an artist and a photographer in a forest, when they unexpectedly encounter a dinosaur. The artist quickly sketches the dinosaur; the photographer snaps a shot. When encountering the drawing and the photograph, we are more likely to believe that the dinosaur exists based on the photo than on the sketch. This is because, due to the mechanical nature of the photographic process, what appears in the photo must also exist in the actual world. The same is not the case with the sketch - the artist perhaps thought that he saw a dinosaur, and sketched that impression, when what he actually witnessed was an intricate play of light in the forest. ${ }^{38}$

It is possible that films made in this way have the same relationship between what actually exists and what is shown on the film and is transposed onto a screen (barring the use of animation or CGI to create a fictional character). ${ }^{39}$ In most movies, film characters depend on an existing person in the actual world to appear on film. This separates film characters from those of literature-in that respect, literary characters are similar to the sketch above; they do not depend on any existing person in the actual world in order to count as one of Thomasson's abstract artifacts.

We can see that the differences between film and literary characters; distinguishing the ontological differences between film and dramatic characters, though, requires more

\footnotetext{
${ }^{38}$ Walton "Transparent Pictures."

${ }^{39}$ Films such as Avatar which use an increasing amount of CGI to develop characters (e.g., the Na'vi) still depend on actors in order to create their characters.
} 
explanation. As suggested above, a film character depends so strongly upon an existing person-some actor who portrays the character throughout the course of a film or several films. Because of this, the film character often becomes inseparable from the actor who portrays him. In our everyday talk about films we so closely associate Harrison Ford with the rebellious Hans Solo, Clark Gable with the charming Rhett Butler or even Angelina Jolie with the rebellious Lara Croft such that a change in actor would be unthinkable. We even go so far as to associate the traits of a character with the actor portraying him, and vice versa. This amounts to the recognition of quality acting, the ability of an actor to take on a certain role in a convincing way, but also that viewers closely relate what actually exists (the actors) to the characters they portray. Replacing Gregory Peck with Jimmy Stewart in To Kill a Mockingbird would be tantamount to changing the character, even though Jimmy Stewart was a fine actor who proved his talent in numerous roles. Thus, Noël Carroll describes film characters and their actors as "non-detachable constituents" of a film. ${ }^{40}$ Changing the actor would not only change the character, but also the film as a whole. The same cannot be said of actors in plays. Ophelia's understudy can take over for a sick star without the character changing in a significant way. The musicals Hairspray, The Phantom of the Opera and Rent have all been performed numerous times and in numerous locations with different actors, all with wild success. Some actors may be better than others in their portrayals, but we would not argue that the character itself is different from performance to performance.

\section{Two cases}

Understanding film characters as abstract artifacts satisfies the intuitions we have

\footnotetext{
${ }^{40}$ Carroll, Noël. The Philosophy of Motion Pictures. Malden, MA: Blackwell Publishing Ltd., 2008.
} 
concerning them introduced in the first section of this paper. Not only do film characters differ from everyday objects because they are abstract, they also seem to differ from those characters found in other art forms because of the unique properties which make up this medium. Furthermore, Thomasson's artifactual theory explains how characters such as Luke Skywalker may appear in more than one film and be easily recognized as the same character in each.

Luke Skywalker presents a straightforward example of a fictional film character persisting across artworks. I will now address two other cases which present more interesting or problematic exampless of characters occurring across different artworks: the possibility of a case in film equivalent to the one Borges presents in "Pierre Menard, Author of the Quixote"; and also recognizing both Richard Harris and Michael Gambon's portrayals of Professor Dumbledore in the Harry Potter series. Each of these cases provides a challenge to the artifactual theory, but one which can, ultimately, be adequately overcome.

Film's Pierre Menard?

Borges' short story "Pierre Menard, Author of the Quixote" is often used as a challenging example by philosophers attempting to explain the identity conditions for literary works. It proved useful above in explaining the difference between Thomasson's definitions of literary text types, compositions and literary works-Pierre Menard and Cervantes wrote the same text type, but not the same composition or literary work. These terms may apply to film as well, clarifying between the material and story standing alone and the artwork in its appropriate social and historical context. Furthermore, considering the Pierre Menard example for literature raises the question about the possibility of such a case in other art forms-is it possible for there to be an analogous case in film? 
There are two main implications of Borges' story which seem to have ramifications for both literature and film as art forms: the question of genuine artistic creativity and the importance of the artist's social and historical context when creating her artwork. To briefly describe Pierre Menard's Quixote: within Borges' story, Menard wrote an unfinished work which consists of the ninth and thirty-eighth chapter of the first part of Don Quixote, and a fragment of the twenty-second. The story itself attempts to "justify...this absurdity." ${ }^{11}$ Utilizing Thomasson's terms, Menard's Quixote-fragment and the coincident chapters of Cervantes' work have the same text-type-though, as the narrator of the story urges, they are not the same composition or literary work. Nor is Menard's Quixote merely a copy of Cervantes': "He did not want to compose another Quixote-which is easy-but the Quixote itself. Needless to say, he never contemplated a mechanical transcription of the original; he did not propose to copy it. His admirable intention was to produce a few pages which would coincide-word for word and line for line-with those of Miguel de Cervantes.." ${ }^{\prime 2}$ Despite the similarity between the two stories, and the fact that Menard was aware of Cervantes' text as he wrote his own, the narrator of the story argues that Menard is nevertheless genuinely creative in his writing - he creates his own literary work.

In fact, the narrator argues, Menard's work is "almost infinitely richer" than the first, though linguistically the stories are identical. The difference between the two Quixote's arises because their authors wrote them in very different historical contexts. This results in different compositions and, thus, different literary works. Consider the following example:

It is a revelation to compare Menard's Don Quixote with Cervantes'. The latter, for example, wrote (part one, chapter nine): '...truth, whose mother is history, rival of time, depository of deeds, witness of the past, exemplar and advisor to the present, and the future's counselor.' Written in the seventeenth century, written by the 'lay genius'

\footnotetext{
${ }^{41}$ Borges 39.

${ }^{42}$ Ibid 39.
} 
Cervantes, this enumeration is a mere rhetorical praise of history. Menard, on the other hand, writes: '...truth, whose mother is history, rival of time, depository of deeds, witness of the past, exemplar and advisor to the present, and the future's counselor.' History, the mother of truth: the idea is astounding, Menard, a contemporary of William James, does not define history as an inquiry into reality but as its origin... ${ }^{43}$

We cannot say, then, that Menard and Cervantes' Quixote's are the same composition or artwork. But are the heroes of each text the exact same Don Quixote? We have here an example of two remarkably similar characters that appear in remarkably similar texts. It also seems that Menard's Quixote satisfies Thomasson's necessary condition for a fictional character appearing in another work.Menard seems to be competently acquainted with Cervante's Don Quixote such that he could import the same character into his own story. How, then, can we call Menard genuinely creative? Unlike the Fielding/Richardson Pamela example, the stories in which the two Don Quixote's appear are textually identical. This, it seems, makes it even easier for a reader to implicitly accept Menard's Quixote as the same character as Cervantes' Quixote, but also more difficult to understand how Menard is genuinely creative in writing his Quixote. As both Borges and Thomasson argue, the creativity must come from the very different historical context Cervantes and Menard occupy.

Consider, now, an analogous case using film instead of literature. Suppose that there exists an amateur film director who so admires Martin Scorsese's The Departed that he sets out to recreate it exactly. He shoots his film in the exact locations in Boston as Scorsese, hires the exact same editors, screenwriters, cinematographers, costume designers, etc., and even manages to convince Leonardo Dicaprio, Jack Nicholson, Vera Farmiga and the rest to agree to recreate this film with him. In the end, this director's The Departed is remarkably similar to Scorsese's-but is it identical?

Because of the unique properties of film as an art form, exact film-type (as opposed to

\footnotetext{
${ }^{43}$ Ibid 43.
} 
text-type) re-creation is impossible. Our amateur director can recreate a scene as close to Scorsese's as possible, but minute details which are beyond our friend's control but which nevertheless make it impossible for him to create an exact film-type as Scorsese's-something as simple as dust or light falling across an actor's face in a different way, or something as significant as Alec Baldwin demanding more film time to make up for his lack of presence in the original, and then walking off the set when realizing his demand will not be granted-bars these two films from being exactly identical.

Perhaps it does not matter that these details are not the same; our director has recreated the same artwork, even without having the same film-type. In terms of our director's intent, which was to recreate Scorsese's The Departed, the films are, for all purposes, the same, and so the characters are the same as well. Even so, as with the Menard example, the historical and social context of our director's film is different than Scorsese's-perhaps, like Menard with the Quixote, our director explicitly or implicitly comments on the subversion of masculinity American mob movies found in Scorsese's film, or even merely desires his film to be an homage to one of the greatest filmmakers of our time.

Most importantly, we can still recognize our director's characters as the same characters in Scorsese's film - as we've seen, complete verisimilitude is not required for character persistence across artworks according to the artifactual theory. A filmmaker must take advantage of his different historical context, utilizing it in such as way as to create his own unique artwork.

\section{The Two Dumbledores}

A film character's dependence on an actual actor, as "non-detachable constituents," 
distinguishes them from dramatic and literary characters, and also helps film viewers to recognize a character from film to film. Mark Hammill plays Luke Skywalker in Star Wars Episodes IV-VI, so we know that Luke is the same Luke in each film. Problems arise for this idea in the less frequent cases of different actors portraying the same character in a series of movies. We have the troublesome case of the two Dumbledore's in the Harry Potter series: Richard Harris portrays the Hogwarts Headmaster in the first two movies; Michael Gambon in the following six. Those who are familiar with these actors know that the switch resulted from Harris's death in 2002. Nevertheless, we can still ask whether or not the two portrayals of Dumbledore amount to the same character across the whole series.

Denying that these are the same character may appear, at first, to be the simple solution to the problem. Harris and Gambon certainly depict different versions of the Professor: Harris's Dumbledore is quieter, gentler and older; Gambon's is livelier, quicker to anger and comical. The two Dumbledores possess significantly different properties in terms of personality traits. We have already seen how Thomasson explains character identity across instances despite changes in property. However, Harry Potter viewers speak of the two actors as the same character, with many of the same properties, narrative history, etc. To say that they are actually different characters would make no sense either in the context of the movie or in our discussion of it.

Arguing that two actors can easily play the same character in a film may, however, present problems ontologically in terms of an artifactual theory, and especially for the argument I have posited concerning fictional film characters as non-detachable constituents closely tied to the actors who portray them. If actors portraying a character can change without (much) confusion, then the distinguishing feature between film and dramatic character is lost-recall 
my argument that many different actors can portray a character in different productions of a single play, or even within the same production, if the lead falls ill and her understudy must rise to the occasion. The goal of the present discussion, then, is to determine how to reconcile the common sense idea that both Harris and Gambon may both portray Professor Dumbledore in the Harry Potter series, while also maintaining the importance of individual actors for film as an art form.

I address two possible explanations. One results from the fact that Dumbledore the character existed as an abstract artifact before the films were made, in J.K. Rowling's novels. The character perhaps persists because the film viewers associate the film character Dumbledore with that of the novel, so a change in actor would not result in a change of character-or, at least, not result in a significant amount of confusion because the audience already has the basis for the character from the novel. The character persists from novel to film, if not from film to film. This explanation, though, takes it for granted that the audience is already familiar with the Harry Potter series, either from having read the novels or from possessing general knowledge of the cultural phenomenon. A viewer who has no previous exposure to the Harry Potter series would not have the adequate knowledge base to make the connection between Dumbledore as the literary figure and Dumbledore as the film character.

Perhaps there is a way to explain how these characters seem the same, but are not actually the same Dumbledore. A less satisfying answer would be that, ontologically, the two Dumbledore's are not the same character, but for the sake of understanding the film series the audience must, on some level, suspend their disbelief that these two characters are the same, and accept the new Dumbledore (Gambon) as the same character. This answer may evoke a certain amount of grumbling from both the audience members who dislike the change in 
character, and from philosophers who want a more robust ontological explanation for how the identity of the character 'Dumbledore' remains with different actors. But from a practical perspective, we must accept Gambon as the new Dumbledore, or else the movies would not make sense and the continuity between them would be somewhat lost or confused. Switching actors for the same character either within the same film or between films in a series is not a desirable option, but a very real one which must be accounted for somehow, as film does rely so strongly on the physical world. Consider also the importance of authorial intention for the necessary condition for characters identity: the author of the sequel (or other work) must be competently acquainted with the original character, but also intend for her character to be the same as the original. This intention, along with our common sense conventions about watching film sequels, overrides the changes in properties from film to film.

\section{Final thoughts}

Understanding film characters as abstract artifacts has, I've argued, the dual benefit of avoiding the ontological problems concerning identity conditions that other theories fall prey to while at the same time preserving a common sense view which appeals to how typical viewers understand these characters. Let's examine once more the four intuitions mentioned in the beginning of the paper which I argue that any theory of film characters must account for:

1. Film characters have a different kind of existence from other ordinary objects of our experience.

2. Film characters appear in more than one story of the same or different medium and can nevertheless still be the same character.

3. Film characters are created.

4. Film characters are, different from characters in other art forms.

5. Everyday audience viewers can meaningfully discuss fictional characters.

Throughout this paper, I have built upon and clarified the first intuition in an attempt to explain 
what a fictional character (of any medium) is. According to the artifactual theory, fictional characters, including film characters, are abstract in the sense that they lack spatio-temporal location. This is the main difference between ordinary objects and fictional ones. Even film characters, with their close association to real actors, cannot be found strolling around the locations in which they purportedly exist. We may be able to find Gwenyth Paltrow in a small town outside of London, but not Emma Woodhouse.

Thomasson's theory also adequately explains how a film character can appear in more than one story, regardless of the medium in which it appears. We can explain this by utilizing her important necessary condition for transtextual character identity. Furthermore, so long as the author of the second work is competently acquainted with the original character, changing the medium of the art form does not seem to be problematic, for changes in property from instance to instance which inevitably occur when transporting a character from one medium to another can be easily explained.

We also have the sense that film characters are different from the characters found in other art forms. Because of film's dependence on the physical world, film characters have a visual existence which literary characters do not. Furthermore, due to the nature of the filmmaking process, we closely associate film characters with the actors who portray them, to such an extent that in many cases we cannot imagine a different actor playing the same role. Using Carroll's terminology, film characters are "non-detachable constituents" of a film, meaning that they cannot be replaced by another actor the way that actors can be replaced in dramatic performances.

Finally, the artifactual theory preserves the notion that everyday viewers can meaningfully discuss fictional characters. This is a problem which the irrealist and Meinongian 
theories struggle with-for how can we meaningfully discuss objects which do not exist? Thomasson's theory-or any realist theory-eliminates this problem by granting fictional characters a certain type of existence which, while not the same ontologically as other ordinary objects, allows us to discuss them with an existing object as the referent. As Thomasson argues, we can discuss fictional characters similarly to how we discuss other abstract artifacts such as scientific theories or governmental laws.

The original concern that allowing abstract artifacts to exist will make for a confusing and overly complicated ontology can be allayed by the idea that fictional characters are not the only sorts of objects which claim this type of existence. As Thomasson suggests, any ontological picture must account for abstracta in some way. Traditional bifurcations between purely real and non-real objects cannot accomplish this. As such, determining the correct ontological status of fictional characters and other abstracta is a worthwhile cause not only for those concerned with the underlying issues of fiction, but for anyone intent on finding an adequate ontological picture in general. 


\section{REFERENCES}

Borges, Jorge Luis. "Pierre Menard, Author of the Quixote." Labyrinths. Trans. James E. Irby. New York: New Directions Publishing Corporation, 1964. 36-44.

Brennan, Andrew. Conditions of Identity. Oxford: Clarendon Press, 1988.

Crittenden, Charles. Unreality: The Metaphysics of Fictional Objects. Ithaca, NY: Cornell University Press, 1991.

Carroll, Noël. The Philosophy of Motion Pictures. Malden, MA: Blackwell Publishing, 2008. Danto, Arthur. "The Artworld." The Journal of Philosophy. Vol 16 (Oct. 1964): 571-584. Lamarque, Peter. The Philosophy of Literature. Malden, MA: Blackwell Publishing, 2009. Lewis, David. "Truth in Fiction." American Philosophical Quarterly. Vol 15 (Jan 1978): 37-46. Meinong, Alexius. "The Theory of Objects." Realism and the Background of Phenomenology. Ed. Roderick M. Chisholm. Glencoe, IL: The Free Press, 1960.

Parsons, Terence. Nonexistent Objects. New Haven: Yale University Press, 1980. Plantinga, Alvin. The Nature of Necessity. Oxford: Oxford University Press, 1974.

Quine, W.V.O. "On what there is." From a Logical Point of View. Cambridge, MA: Harvard University Press, 1953.

Sainsbury, R.M. Fiction and Fictionalism. New York: Routledge, 2010.

Thomasson, Amie L. Fiction and Metaphysics. New York: Cambridge University Press, 1999. Thomson-Jones, Katherine. Aesthetics and Film. London: Continuum International Publishing Group, 2008.

Walton, Kendall L. "Fearing fictions." Philosophy of Film and Motion Pictures. Ed. Noël Carroll and Jinhee Choi. Malden, MA: Blackwell Publishing Ltd, 2006. 234-246. 
Mimesis as Make-Believe. Cambridge, MA: Harvard University Press, 1990.

“Transparent Pictures." Critical Inquiry, Vol. 11, No. 2 (Dec. 1984), pp. 246-277.

Zalta, Edward N. "Referring to Fictional Characters." Dialectica. Vol. 57 (2003): 243-254.

<http://mally.stanford.edu/Papers/refer-to-fictions.pdf $>$.

Zemach, Eddy. "Tom Sawyer and the Beige Unicorn." The British Journal of Aesthetics. Vol 38

(April 1998): 167-180. 
Tullmann, Katherine C. 2010, UMSL, p. 35

\section{NOTES}

\footnotetext{
'As mentioned, many philosophers have posited different theories concerning fictional entities. It is beyond the scope of this paper to explore these in detail, but some clarification is warranted. There are three main categories of theories: irrealist theories, Meinongian theories and possibilist theories. The irrealist theories are best represented by Quine and Russell, and Kendall Walton more recently. These theories maintain that fictional entities do not exist-and when referring to them, there is no "thing" to which we refer, rendering such discussions meaningless. Walton's pretense theory gets around this by arguing that our engagement with fictions is analogous to a complex game of make-believe, making the audience participants in a fictional world, and characters props in that world.

Meinongian theories are based on the German philosopher Alexius Meinong who argued that fictional objects, like abstracta such as pure geometrical forms, do not exist, but do subsist. More recently, Terence Parsons has argued that fictional characters exist in an ever present, unchanging realm of ideal objects, similar to a Platonistic realm, to which every person has access. Authors then "pick out" characters from this realm and incorporate them in to their stories.

Possibilist theories, favored by modal realists such as David Lewis, hold that fictional characters do not exist in our actual world, but rather as unactualized possible objects from another world-though unactualized in our world, they do exist somewhere. This is also a view once supported by Alvin Plantinga, who states that "Hamlet and Lear do not in fact exist, but clearly they could have. So there must be possible worlds in which Lear and Hamlet exist, hence they are possible but not actual objects."

Each of these theories deserves discussion and analysis which is beyond the scope of this paper to provide. My main critique of these theories results from the five intuitions listed above-all three of these theories fail to account for one or more of these intuitions.
} 